\title{
Channels and Transmitters Involved in Trigeminal Nociception
}

\author{
Van der Cruyssen Fréderic ${ }^{1 *}$, Verhelst Pieter-Jan ${ }^{1}$ and Politis Constantinus ${ }^{1}$ \\ ${ }^{1}$ Department of Imaging and Pathology \& Department of Maxillofacial Surgery, Catholic University Leuven and University Hospitals, Leuven, Belgium
}

Received: January 09, 2018; Published: February 02, 2018

*Corresponding author: Van der Cruyssen Fréderic, Department of Imaging and Pathology \& Department of Maxillofacial Surgery, Catholic

University Leuven and University Hospitals, Leuven, Belgium, Email: frederic.vandercruyssen@uzleuven.be

\begin{abstract}
The understanding of pain and its underlying pathophysiology remains an active research area. We aim to review the most recent insights in molecular pathways involved in nociception of the trigeminal sensory system, more specifically we focus on channels and neurotransmitters. We review the molecular pathways of inflammatory nociception.
\end{abstract}

\section{Introduction}

Nociception in the trigeminal sensory system is mainly conveyed via mechano, thermo, and polymodal nociceptors through $\mathrm{A} \delta$ and $\mathrm{C}$ fibers with the primary pseudounipolar neurons having their cell body in the trigeminal ganglion (TG). From the trigeminal ganglion these fibers segregate in a somatotopic way to their respective trigeminal nuclei where they synaps and project mainly towards the ventroposterior

medial nucleus of the thalamus (Figure 1). Most C-fibers descend toward the subnucleus caudalis of the trigeminal nuclear complex. Tertiary fibers project towards the somatosensory cortex. Cross innervations with other nuclei, spinal cord and projections to cerebellum and superior colliculus are being investigated, as well as projections to the amygdala, responsible for aversive experiences.

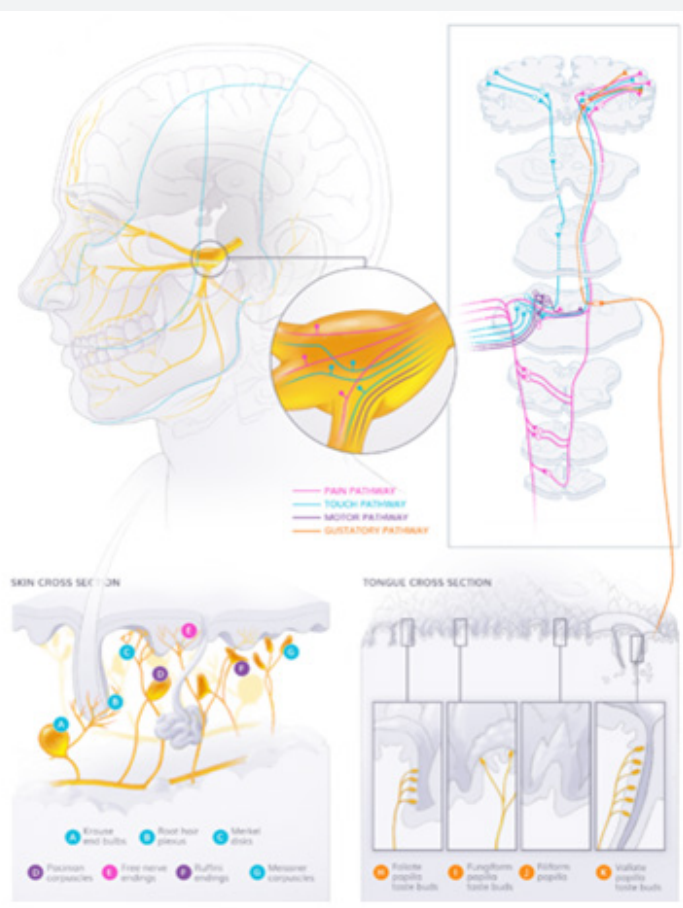

Figure 1: Anatomic and subanatomic overview of the trigeminal system with its specialized nerve endings, trigeminal ganglion and central projections to thalamus and somatosensory cortex. 
Molecular physiology of trigeminal nociception is an active area of investigation mainly involving animal models. Acute pain perception mainly involves conduction through unmyelinated $\mathrm{C}$-fibers and thin myelinated A $\delta$-fibers. Subpopulations exist between the C-fibers: peptidergic $\mathrm{C}$ nociceptors, releasing neuropeptides, and non-peptidergic C-nociceptors such as c-Ret neurothrophin receptor expressing fibers. A $\beta$-fibers play a more important role in referred pain and mechanical allodynia where primary A $\beta$-fibers synaps with C-fibers. The mechanisms which transform acute pain into chronic pain still need further exploration. Clinical observations show the robustness of the trigeminal system due to the low incidence of neuropathic pain and the reversibility of emerging neuropathic pain in the area of the inferior alveolar nerve.

\section{Discussion}

Peripheral trauma induces tissue inflammation which triggers the nociceptive pathway through release of local mediators such as cytokines, amino acids, bradykinin, calcitonin gene-related peptide (CGRP), substance P, nitric oxide (NO) and neuropeptide Y (NPY) [1]. Adenosine triphosphate (ATP) signal transduction induces both nerve cells and glial satellite cells, being regulated by vesicular nucleotide transporter (VNUT). VNUT has an important role in exocytic release of ATP, which promotes neural depolarization [2]. Nociceptive C-fibers are able to release CGRP and Substance P facilitating in neurogenic inflammation and thus functioning as a positive feedback loop. CGRP is capable of inducing mast cell degranulation as well as P2X3 gene expression in trigeminal ganglia neurons [3]. Our clinical observations in nerve damage show that transection of inferior alveolar nerve results in hypoesthesia but rarely in dysesthesia, whereas crushing of the inferior alveolar nerve often results in less hypoesthesia but more frequent dysesthesia, which occasionally transforms to irreversible neuropathic pain when a solution cannot be found before the critical time window of 3 months. The hypothesis is that traumatized axons lose their myelin cover allowing neurogenic inflammation to affect demyelinated axons with or without ephaptic transmission of impulses.

P2X3, purinoreceptor 3 , is activated by extracellular ATP which promotes primary neuron depolarization [4]. Induction of P2X3 gene expression by CGRP is possible through the cAMPsignaling cascade as well as paracrine activation of BDNF gene. BDNF on itself promotes P2X3 expression. CGRP and NO cause up regulation of neurokinin 1 (NK1) which lowers the threshold potential of TG cells. These NK1 receptors are also present in the glial cells [1]. Release of interleukins such as IL-1 $\beta$ suppress voltage gated potassium channels through protein kinase coupled pathways further increasing the neural excitability. NK1 blockade at the TG has been showed effective in preventing central sensitization.

Transient receptor potential (TRP) channels that are temperature-sensitive are also modulated by peripheral inflammation. More specifically, TRPV1 and TRPA1 are expressed in nociceptors [5,6]. TRPA1 responds to noxious electrophilic stimuli and is sensitized by inflammation, it also responds to cold stimuli by which it could play a role in cold allodynia. TRPV1 has been shown important in heat allodynia and is up regulated by inflammatory mediators. Various GPCR's are activated by peripheral inflammation and start the intracellular cascade by coupling Gq and PLC $\beta$ enzymes [7]. Examples of GPCR's responding to inflammation are bradykinin receptors B1 and B2, purinergic P2Y receptors, chemokine receptors and prostaglandin receptors (EP1), lysophosphatidic acid (LPA) receptors and proteinase-activated (PAR) receptors.

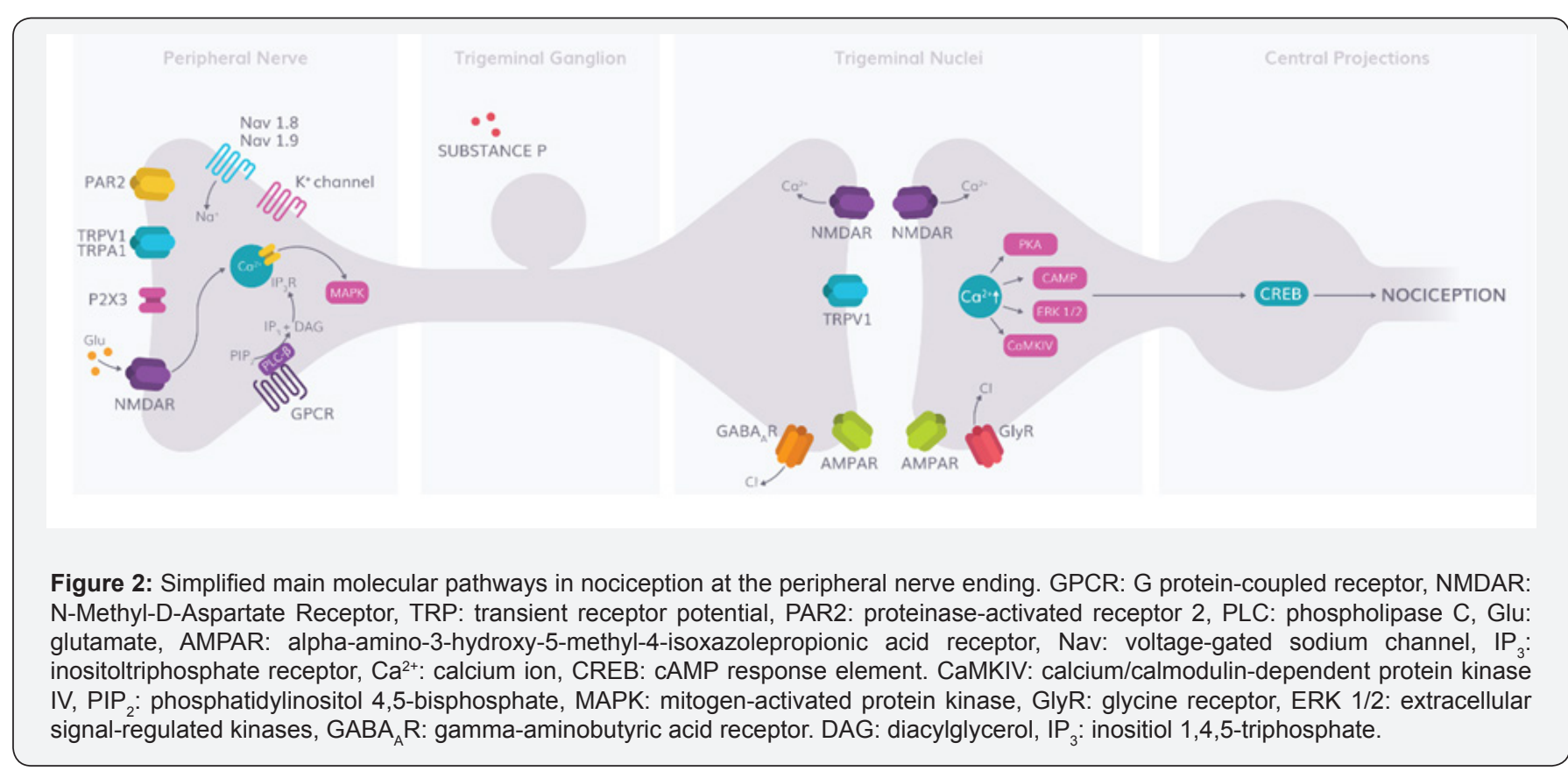


They are able to sensitize and modulate the pain pathway. Their exact role in the pain cascade needs further investigation. PAR2 receptors, expressed by a large portion of primary afferents, respond to injury and inflammation. PAR2 knockout models in chronic constriction models prevent development of neuronal hyper excitability. However, once hyper excitability is present, reduction of hyper excitability by PAR2 selective inhibition is non-reversible [8]. PAR2 further modulates the cAMP signaling cascade. Research on human lingual nerve neuromas showed the importance of two sodium protein channels, Nav 1.8 and Nav 1.9 which are voltage-gated [9]. Nav 1.8 expression levels correlated with severity of pain, knock-out models attenuate pain sensation in neuropathic pain mouse models.

The role of Nav 1.9 is less well understood in the development of neuropathic pain. These voltage-gated sodium channels, as well as voltage-gated calcium channels, are of major importance in generating the action potential to depolarize the primary neuron. At the level of the subnucleus caudalis the wide dynamic range neuron plays a major role in nociceptive signaling. C-fibers release substance P and glutamate, activating this neuron. Glutamate binds the NMDA and AMPA receptors, whereas substance $\mathrm{P}$ has affinity for the NK-1 receptor. Subsequently, intracellular mechanisms are triggered by protein kinase A (PKA) and protein kinase C (PKC) activation. Release of prostaglandins through cyclo-oxygenase and NO via nitric oxide synthase [10]. Glial cells participate through release of prostaglandins, IL-1 $\beta$, after ATP activation and regulation by VNUT. They also express P2Y12, a G protein-coupled receptor (GCPR), and NK1 receptors which are up regulated when nerve inflammation occurs. Descending pathways regulate release of serotonin and noradrenalin. Inhibitory regulation occurs through release of GABA and glycine.

\section{Conclusion}

The most recent advances on molecular mechanisms in trigeminal nociception were reviewed. We highlighted the importance of CGRP and TRP channels as well as positive feedback loops in the inflammatory pain cascade and correlated these findings with clinical reality. The role of glial cell and its interaction with neurons becomes increasingly important in understanding the molecular biology of pain.

\section{References}

1. Takeda M, Matsumoto S, Sessle BJ, Shinoda M, Iwata K (2011) Peripheral and Central Mechanisms of Trigeminal Neuropathic and Inflammatory Pain. J Oral Biosci 53(4): 318-329.

2. Masuda T, Ozono Y, Mikuriya S, Kohro Y, Tozaki-Saitoh H, et al. (2016) Dorsal horn neurons release extracellular ATP in a VNUT-dependent manner that underlies neuropathic pain. Nat Commun 7: 12529.

3. Russo AF (2015) (CGRP): A New Target for Migraine. Annu Rev Pharmacol Toxicol 55: 533-552.

4. Fabbretti E (2017) ATP-Gated P2X3 Receptors Are Specialised Sensors of the Extracellular Environment. Adv Exp Med Biol - Protein Rev. 1051:7-16.

5. Dubin AE, Patapoutian A (2010) Nociceptors: The sensors of the pain pathway. J Clin Invest 120(11): 3760-3772.

6. Cortright DN, Krause JE, Broom DC (2007) TRP channels: targets for the relief of pain. Biochim Biophys Acta 1772(8): 989-1003.

7. Stone LS, Molliver DC (2009) In search of analgesia: emerging roles of GPCRs in pain. Mol Interv 9(5): 234-251.

8. Huang ZJ, Li HC, Cowan AA, Liu S, Zhang YK, et al. (2012) Chronic compression or acute dissociation of dorsal root ganglion induces cAMP-dependent neuronal hyperexcitability through activation of PAR2. Pain 153(7): 1426-1437.

9. Bird EV, Christmas CR, Loescher AR, Smith KG, Robinson PP, et al. (2013) Correlation of Nav1.8 and Nav1.9 sodium channel expression with neuropathic pain in human subjects with lingual nerve neuromas. Mol Pain 9:52.

10. Miclescu A, Gordh T (2009) Nitric oxide and pain: Something old, something new. Acta Anaesthesiol Scand 53(9): 1107-1120.

\section{Your next submission with Juniper Publishers will reach you the below assets}

- Quality Editorial service

- Swift Peer Review

- Reprints availability

- E-prints Service

- Manuscript Podcast for convenient understanding

- Global attainment for your research

- Manuscript accessibility in different formats

( Pdf, E-pub, Full Text, Audio)

- Unceasing customer service

Track the below URL for one-step submission https://juniperpublishers.com/online-submission.php 